
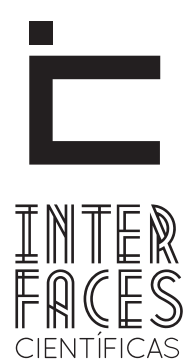

EDUCAÇÃO

ISSN IMPRESSO 2316-333X

ISSN ELETRÔNICO 2316-3828

\title{
FORMAÇ̃̃O INICIAL DE PROFESSOR E PRÁTICA REFLEXIVA: UM ESTUDO NO CONTEXTO DAS TEORIAS MOTIVACIONAIS CONTEMPORÂNEAS
}

Marilene Batista da Cruz Nascimento ${ }^{1}$

Josevânia Teixeira Guedes ${ }^{3}$
Bettina Steren dos Santos ${ }^{2}$

\section{RESUMO}

Esta pesquisa tem como objetivo discutir as inter-relações entre as teorias contemporâneas motivacionais no contexto da formação inicial de professores, visando compreender os significados e as peculiaridades desse cenário. Trata-se de um estudo teórico, de cunho bibliográfico, que evidencia as contribuições dos processos motivacionais para a formação docente. A motivação retrata um processo que antecede a ação humana, de forma intrínseca e extrínseca, e possibilita inferir que o saber docente não se reduz, exclusiva ou principalmente, a processos mentais, cujo suporte é a atividade cognitiva dos indivíduos, mas é, também, um saber social que se manifesta nas relações complexas entre docentes e estudantes. Por fim, concluiu-se que há uma relação intrínseca entre a ciência pedagógica, a prática reflexiva e a motivação como instrumento para uma formação diferente da que se tem atualmente. Realidade essa que justifica a presença das teorias motivacionais na formação básica dos professores.

\section{PALAVRAS-CHAVE}

Formação Inicial. Prática Reflexiva. Processos Motivacionais. 


\section{ABSTRACT}

This research aims to discuss the interrelationships between contemporary motivational theories in the context of initial teacher training, to understand the meanings and the peculiarities of this scenario. This is a theoretical study of bibliographic nature, which highlights the contributions of motivational processes for teacher training. The motivation portrays a process that precedes human action, intrinsic and extrinsic form, and allows us to infer that teacher knowledge is not limited exclusively or mainly to mental processes, whose support is the cognitive activity among people, but is also a social knowled- ge manifested in complex relationships between teachers and students. Finally, it was concluded that there is an intrinsic relationship between pedagogical science, reflective practice and motivation as a tool for training a distinct way from what we currently have. This fact justifies the presence of motivational theories in basic teacher training.

\section{KEYWORDS}

Initial Training. Reflective Practice. Motivational Processes.

\section{RESUMEN}

Esta investigación tiene como objetivo, analizar las interrelaciones entre las teorías motivacionales contemporáneas en el contexto de la formación inicial del profesorado, con el objetivo de comprender los significados y las peculiaridades de este escenario. Se trata de un estudio teórico de la naturaleza bibliográfica, que aporta destaque a los procesos de motivación para la formación del profesorado. La motivación representa un proceso que precede a la acción humana, bajo la forma intrínseca y extrínseca, y nos permite inferir que el conocimiento docente no se limita exclusivamente a los procesos mentales, cuyo apoyo es la actividad cognitiva de los individuos, sino también un conocimiento social, manifestado en la compleja relación entre profesores y estudiantes. Finalmente, se llegó a la conclusión de que existe una relación intrínseca entre la ciencia pedagógica, la práctica reflexiva y la motivación como herramienta para una formación diferente de la que tenemos hoy. Una realidad que justifica la presencia de las teorías motivacionales en la formación básica del profesorado.

\section{PALAVRAS CLAVE}

Formación inicial. Práctica reflexiva. Procesos motivacionales 


\section{CONSIDERAÇÕES INICIAIS}

Este estudo tem por objetivo discutir as inter-relações entre as teorias contemporâneas motivacionais no contexto da formação inicial de professores, visando compreender os significados e as peculiaridades desse cenário. Essa conjuntura permite um pensar e um repensar da formação docente em uma realidade complexa que envolve questões acerca de saberes científicos, pedagógicos e emocionais.

Justifica este estudo teórico, de cunho bibliográfico, o fato de que relacionar formação inicial de professores com os processos motivacionais, que permitem uma discussão sobre a concepção do professor como profissional reflexivo e da reflexão-na-ação como estratégia que fundamenta a epistemologia da prática, com suas repercussões, tanto do ponto de vista emocional, quanto da formação de professores.

Entende-se que os conhecimentos e os saberes não se limitam à cognição. Essa tem relação com interações sociais e emocionais que se manifestam entre professores e estudantes. As aprendizagens possibilitam uma imersão de novas formas de pensar o ensino. Em outras palavras, a atividade docente configura-se pela constante problematização, inclusive em sala de aula, sendo marcada pela reflexão contínua dos aspectos emocionais. 0 aprendizado do professor é definido como uma atividade dinâmica que se dá por meio do diálogo entre a ação, a reflexão e os processos motivacionais.

\section{A FORMAÇÃO INICIAL DE PROFESSOR E OS PROCESSOS MOTIVACIONAIS}

A Lei de Diretrizes e Bases da Educação Nacional (LDBEN) no. 9.394 de 1996 disciplina a educação escolar que se desenvolve por meio do ensino e em instituições próprias, vinculando-se, em tese, ao mundo do trabalho e à prática social. Essa lei promoveu mudanças nas normatizações e concepções da educação brasileira, dentre as quais se destaca a proclamada valorização dos profissionais dessa área.

Em suas Disposições Gerais, no Capítulo II, Seção I, a LDBEN nº 9.394 de 1996 regulamentam a finalidade da educação básica, prevendo que deve ser assegurada ao aluno uma formação comum, indispensável para o exercício da cidadania, que inclua a difusão de valores basilares ao interesse social, os direitos e deveres dos cidadãos, o desenvolvimento da capacidade de aprender - tendo como meios básicos o pleno domínio da leitura, da escrita e do cálculo - a compreensão do ambiente natural e social, do sistema político, da tecnologia, das artes e dos valores em que se fundamenta a sociedade (BRASIL, 1997). Entre outros preceitos, o referido capítulo também trata dos conteúdos curriculares da educação básica (educação infantil, ensino fundamental e médio, educação de jovens e adultos), enfatizando as condições de escolaridade, a orientação para o trabalho e a promoção do desporto educacional.

Essa situação nos remete à reflexão sobre como a LDBEN nº 9.394 de 1996 sistematiza a formação inicial dos profissionais da educação para que possa atender aos objetivos dos diferentes níveis e modalidades de ensino e às características das fases do desenvolvimento dos alunos em sua trajetória escolar proposta também nessa lei. O capítulo V, Título VI, apresenta sete artigos acerca dos profissionais de educação. Em linhas gerais, trata da capacitação em serviço, do aproveitamento da formação e experiências anteriores em instituições de ensino e da valorização por meio de estatutos e planos de carreira. Especialmente, o Art. 62 sinaliza que:

\footnotetext{
A formação de docentes para atuar na educação básica far-se-á em nível superior, em curso de licenciatura, de graduação plena, em universidades ou institutos superiores de educação, admitida, como formação mínima para o exercício do magistério na educação infantil e nas quatro primeiras séries do ensino fundamental, oferecida em nível médio, na modalidade Normal. (BRASIL, 1997, p. 36).
} 
Essa normatização leva a questionar: será que as licenciaturas, conforme preconiza a atual LDBEN, têm estimulado uma formação capaz de desenvolver nos professores a disposição de investigar a própria prática, ressignificando os saberes-fazeres docentes, num processo contínuo de construção de suas identidades como professores? E como os estudos dos processos motivacionais são considerados no trabalho docente?

A natureza do trabalho docente se configura pela via de dois processos em dialogicidade: o ensinar e o aprender, de modo a contribuir para o processo de humanização dos alunos, dos próprios professores (eternos aprendizes) e da sociedade. Assim, espera-se da licenciatura a capacidade de desenvolver nos estudantes conhecimentos e habilidades, atitudes e valores que thes permitam construir seus próprios saberes e fazeres docentes a partir das necessidades e dos desafios postos pelo ensino como prática social do cotidiano (PIMENTA, 2005).

Entende-se por trabalho docente a práxis, marcada pela associação teoria e prática, que se pauta na ação-reflexão-ação, também compreendido como um processo que emerge do estudo de sua gênese, de suas condições históricas gerais - o trabalho como forma histórica - e com suas particularidades (o cotidiano da ação docente), corroborando o pensamento de Azzi (2000).

Na perspectiva do trabalho docente, torna-se interessante abordar a formação inicial de professores no contexto dos processos motivacionais. Para tratar da motivação, que é algo que tem ligação direta com o eu/self, deve-se levar em conta as diversas situações em que o termo é utilizado e o que, particularmente, se compreende sobre um professor motivado.

Huertas (2001, p. 69) apresenta as perspectivas dos teóricos da Psicologia, mas, em outro momento, o estudioso se pergunta sobre "[] que es esa cosa llamada motivación y de cómo se conforma y actúa la motivación en conciencia humana”. O autor dedica-se a rever os principais marcos de referência do estudo desse comportamento do ser humano e o diferencial, inicialmente do instinto animal ao motivo humano.

Assim, a motivação seria o processo que antecede a ação humana, ora de forma intrínseca, relacionada ao interesse pela tarefa com um fim em si mesmo. Ora de forma extrínseca, quando a atenção à tarefa corresponde com a conquista da meta. Ou seja, motivação é “[...] um ensaio mental de uma ação para animar-se e executá-la com interesse e diligência" (HUERTAS, 2001, p. 48).

Santos e outros autores (2007b) afirmam que os processos motivacionais englobam motivos internos e externos de cada pessoa, construídos a partir das inter-relações sociais. Isso significa que para uma nova situação vivenciada, novos motivos poderão surgir, tornando-se relevante compreender o ser humano com suas características e subjetividades. Então, a motivação pode ser entendida como

\begin{abstract}
[...] um processo que cada ser humano apreende de formas distintas, em virtude de suas relações interpessoais e intrapessoais. Desde a infância, as interações com outros seres humanos irão contribuir, mas não de forma determinista, à internalização dos motivos intrínsecos do indivíduo em sua diversidade, a menos que novos motivos extrínsecos possam revelar-se em renovados processos motivacionais internalizados. (SANTOS; ANTUNES, 2007a, p. 156).
\end{abstract}

Timm (2010, p. 103) faz uma reflexão sobre a motivação docente e a inicia com uma frase definitiva naquilo que traduziria o profissional formado, autônomo e consciente de sua missão, isto é, aquele que diria: "[...] sou professor, porque isso me faz bem". Esse sentir-se bem quer dizer que esse indivíduo está motivado. Tal contexto é diferente de outro em que o docente apresentaria um discurso no qual sua palavra seria: “Escolhi. Agora não dá mais pra voltar” (TIMM, 2010, p. 106). 
Fossatti (2010) considera as perspectivas da motivação como elemento substancial para a produção de sentido na docência. A visão desse estudioso é nova e abrangente. Frise-se a importância da palavra sentido para essa contextualização do professor na sociedade atual, ainda mais dramática do que em outros momentos, uma vez que há uma reviravolta em todos os setores, enquanto à profissão do educador só se promete uma espécie de descartabilidade e mesmo de extinção da espécie, diga-se, figurativamente, dessa forma. Fossatti (2010, p. 53) desenvolveu o conceito de logoformação, como sendo a capacidade do indivíduo "[...] voltar a compreender a pessoa como um todo e cuidar desse todo [...]", o que seria a garantia da atribuição do sentido. Em outras palavras,

Como decorrência, a pessoa colheria os frutos de êxito, bem-estar, sucesso, alegria, ética, felicidade e tantos outros atributos que deixam a vida mais bela e qualificada, pelos relacionamentos saudáveis construídos entre um eu e um tu, em contínua comunicação e transcendência. Assim, abriríamos sulcos para plasmar uma nova estética da existência movida pela força do sentido. Nessa compreensão, relacionamento saudável, bem-estar, êxito no amor e no trabalho tornam-se, simplesmente, expressões de uma vida vivida com sentido. (FOSSATTI, 2010, p. 53).

0 autor acrescenta que, os sujeitos não recebem a suposta graça de uma vida melhor apenas em virtude de trabalharem, mas porque entendem o trabalho como um 'meio' de galgar espaços para uma vida melhor na qual consegue bens desejados e antes inalcançáveis. Este estado de 'coisas' implica declínio da vocação e da idealização profissional. Portanto, “[...] decai a ideia da realização profissional em favor da busca pela satisfação mais imediata de desejos e necessidades ou pelo acesso mais imediato a bens e serviços que atendem a um modelo de consumo mais efêmero" (PEREIRA, 2010, p. 62).

Essa é a realidade em que se entrechocam valores e forças contrárias, ambiente no qual o professor, aturdido, fragmenta-se como indivíduo e não sabe a que e a quem atender se à nobreza de ser um educador ou à falta de ética em ceder a uma situação emergencial traduzida na aquisição de bens frágeis, sem os quais a sociedade de consumo o expele e apequena.

Essa dinâmica faz o trabalho docente adquirir novas peculiaridades continuamente para atender às demandas socialmente necessárias. As sociedades contemporâneas prestigiam uma profissão mediante sua visibilidade social. No caso do ser professor, esse fato torna-se decisivo para o fortalecimento e sustentação dessa profissão, bem como da qualidade do trabalho interno nas escolas e da sua capacidade de intervir na comunidade externa.

Essas reflexões defendem uma formação inicial de professores construída, considerando os processos motivacionais, ou seja, combinar as contribuições científicas, pedagógicas, emocionais e técnicas a partir dos próprios docentes e tendo a escola como espaço dessa formação, reconhecendo a experiência dos demais profissionais da área. Esses argumentos são suficientes para sustentar o conceito de logoformação (FOSSATI, 2010), baseando-se também em uma prática reflexiva.

\section{TEORIAS CONTEMPORÂNEAS DA MOTIVAÇ̃̃O E PRÁTICA REFLEXIVA}

As teorias contemporâneas constituem-se como elementos essenciais no contexto da formação inicial de professor, pela especificidade da função do educador que deve ser pensada e repensada nesse bojo. A sociedade exige um profissional capaz de refletir acerca da sua práxis a fim de tomar por "[...] base as circunstâncias concretas, participar da organização coletiva em busca da construção de alternativas que articulem a educação aos demais processos de desenvolvimento e consolidação de relações sociais verdadeiramente democráticas” (KUENZER, 1998, p. 2).

Segundo a autora, o que atribui essa especificidade à função do educador é o fato de se entender a história dos processos pedagógicos, a produção teó- 
rica e a organização de práticas pedagógicas, numa perspectiva de buscar ferramentas que permitam a construção de categorias de análise. Essa construção possibilita uma apropriação das concepções presentes nas relações sociais e produtivas de cada época. Ou seja, a tarefa do educador perpassa pela capacidade de

[...] transformar o conhecimento social e historicamente produzido em saber escolar, selecionando e organizando conteúdos a serem trabalhados através de formas metodológicas adequadas; construir formas de organização e gestão dos sistemas de ensino nos vários níveis e modalidades; e, finalmente, no fazer deste processo de produção de conhecimento, sempre coletivo, participar como um dos atores da organização de projetos educativos, escolares e não-escolares, que expressem o desejo coletivo da sociedade. (KUENZER, 1998, p. 3).

Essa discussão indica a fuga da educação do campo do modismo. Na linha da ciência pedagógica, as práticas pedagógicas seguem saberes relacionados à história cultural e social o que obriga uma reflexão sobre a moda dos interesses neoliberais dos progressistas que colocam no centro da ação educativa a escola e a comunidade; famílias e organizações sociais; a sociedade difusa dos empresários; mídia e os amigos da escola (ARROYO, 2000).
Para o pesquisador, esse processo descaracteriza a ação educativa e retira o foco dos espaços e das estratégias pertinentes à formação do professor reflexivo e ainda representa a reafirmação da especialidade da ação, do ofício, do planejamento, quando a educação é um direito social e as políticas de formação e de currículo precisam buscar referências no passado, na memória e na história.

Nessa condição, a atuação docente, e, por conseguinte, a formação de professor envolve uma diversidade de espaços, experiências, convivências, escothas que se relacionam no ser e no fazer do professor. São pensamentos, concepções, valores, culturas e significados que quando registrados exploram dimensões pessoais e do coletivo. Esse cenário traz a possibilidade de discutir as teorias contemporâneas, especificamente a Teoria da Autodeterminação, Teoria das Metas de Realização e a Teoria da Perspectiva de Tempo Futuro.

A Teoria da Autodeterminação de autoria de Edward Deci e Richard Ryan, nos meados de 1970, estabelece uma relação entre os tipos de motivação: amotivação, motivação intrínseca e extrínseca, conforme quadro a seguir:

Tabela 1 - Tipos de Motivação

\begin{tabular}{|c|c|c|c|c|c|c|}
\hline \multicolumn{7}{|c|}{ Tipos de motivação } \\
\hline & Amotivação & \multicolumn{4}{|c|}{ Motivação Extrínseca } & Motivação \\
\hline Comportamento & Ausência de & \multicolumn{4}{|c|}{ Controlado externamente } & Autodeterminado \\
\hline $\begin{array}{c}\text { Estilos } \\
\text { Reguladores }\end{array}$ & Sem Regulação & $\begin{array}{l}\text { Regulação } \\
\text { Externa }\end{array}$ & $\begin{array}{l}\text { Regulação } \\
\text { Introjetada }\end{array}$ & $\begin{array}{c}\text { Regulação } \\
\text { Identificada }\end{array}$ & $\begin{array}{c}\text { Regulação } \\
\text { Integrada }\end{array}$ & $\begin{array}{l}\text { Regulação } \\
\text { Intrínseca }\end{array}$ \\
\hline $\begin{array}{l}\text { Percepção do } \\
\text { Lócus de } \\
\text { Causalidade }\end{array}$ & Impessoal & Externo & $\begin{array}{c}\text { Parcialmente } \\
\text { Externo }\end{array}$ & $\begin{array}{c}\text { Parcialmente } \\
\text { Interno }\end{array}$ & Interno & Interno \\
\hline $\begin{array}{l}\text { Características } \\
\text { do Processo }\end{array}$ & $\begin{array}{l}\text { Não intencional; } \\
\text { Desvalorizado; } \\
\text { Sentimento de } \\
\text { incompetência; } \\
\text { falta de controle. }\end{array}$ & $\begin{array}{l}\text { Submissão; } \\
\text { Recompensas } \\
\text { externas; } \\
\text { punições. }\end{array}$ & $\begin{array}{c}\text { Autocontrole; } \\
\text { Ego- } \\
\text { envolvimento; } \\
\text { Recompensas } \\
\text { internas; } \\
\text { punições }\end{array}$ & $\begin{array}{l}\text { Importância } \\
\text { pessoal; } \\
\text { Valorização } \\
\text { consciente. }\end{array}$ & $\begin{array}{c}\text { Congruência; } \\
\text { Conscientização; } \\
\text { Sintonia com a } \\
\text { vontade pessoal. }\end{array}$ & $\begin{array}{l}\text { Interesse, prazer } \\
\text { e satisfação } \\
\text { inerente. }\end{array}$ \\
\hline
\end{tabular}

Fonte: Deci e Ryan (1985 apud SANTOS, 2011). 
A motivação intrínseca é entendida como um comportamento autodeterminado, tendo sua ação norteada pela livre escolha, pela espontaneidade e pela curiosidade. 0 interesse dedicado para a realização de uma atividade está nas características inerentes à própria atividade, conforme explicita as informações do quadro. Já na motivação extrínseca, a tarefa depende da obtenção de um resultado. Segundo os autores (DECl; RYAN, 1985, 2000 apud SANTOS 2011), a realização das atividades tem relação com recompensas, avaliações, prazos, punições, elogios etc. 0 comportamento é determinado pela associação ao controle e desejos externos, no qual o sujeito atua para alcançar o objetivo.

Santos (2011, p. 396) afirma que essa teoria,

Tornou-se amplamente aceita e difundida em diversos campos do conhecimento, sobretudo no contexto acadêmico. Seu foco de análise reside na orientação dos motivos que dirigem os comportamentos, estabelecendo para esses diferentes lócus de causalidade: o interno e o externo. Desse binômio surgem as duas principais orientações motivacionais que fundamentam a teoria - a motivação intrínseca e a extrínseca.

Essas características do processo da motivação do sujeito têm relação com o externo (submissão, recompensas externas, punições etc) e com as ações autodeterminadas (interesse, prazer e satisfação inerente a si mesmo).

A Teoria das Metas de Realização surgiu também na década de 1970, tendo como principais colaboradores Carole Ames, Carol Dweck, Martin Maehr e John Nicholls. Essa teoria avalia como a adoção de metas gera diferentes modelos motivacionais nos alunos (ELLIOT, 2005), adotando dois tipos de metas: meta aprender e meta de desempenho.

A meta aprender está caracterizada pelo desejo de buscar novos conhecimentos, destrezas e competências. Ao incorporar isso, o aluno direciona mais energia para o enfrentamento das atividades, valorizando a própria atividade e o processo a ela inerente, além de utilizar estratégias metacognitivas e atribuir o sucesso ao próprio esforço. Já a meta desempenho, também conhecida como meta relacionada ao ego, está pautada pelo desejo de sentir-se bem frente aos outros ou pelo desejo de não sentir-se incapaz. Nessa, o que prevalece é a obtenção de uma meta/objetivo, contexto em que a realização das tarefas assume uma importância secundária. 0 sentido da realização de uma atividade/tarefa está condicionada à obtenção de uma meta/objetivo final, estando esse tipo de comportamento muito associado à instalação de ambientes competitivos. (SANTOS, 2011, p. 398).

As concepções dessa teoria sinalizam uma necessidade de educador reflexivo, que seja capaz de compreender a realidade, apoiando-se nas distintas áreas do conhecimento para entender os processos motivacionais do aluno; ressignificar práticas educativas, privilegiando os conteúdos necessários e as adequadas formas metodológicas e que em uma perspectiva reflexiva acompanhe de forma crítica a vontade coletiva (KUENZER, 1998).

A Teoria da Perspectiva de Tempo Futuro está estruturada nos estudos do psicólogo Joseph Nuttin. Para Nuttin (1985, p. 135), a motivação é “[...] uma tendência específica em direção a um determinado objeto e sua intensidade está em função da natureza e da relação que o sujeito mantém com esse objeto". Santos (2011) analisa esse comportamento a partir do surgimento dinâmico de uma necessidade do sujeito identificar seus objetos desejados para pensar projetos de ação. "0 objetivo e o projeto de ação se relacionam com a noção de perspectiva futura. [...] o futuro psicológico é essencialmente relacionado com a motivação" (SANTOS, 2011, p. 399).

Para Lens (1993), essa teoria integra o futuro cronológico no presente psicológico do sujeito, abordando três níveis de perspectiva futura: extensa, restrita e prolongada. Observe o Mapa mental a seguir: 


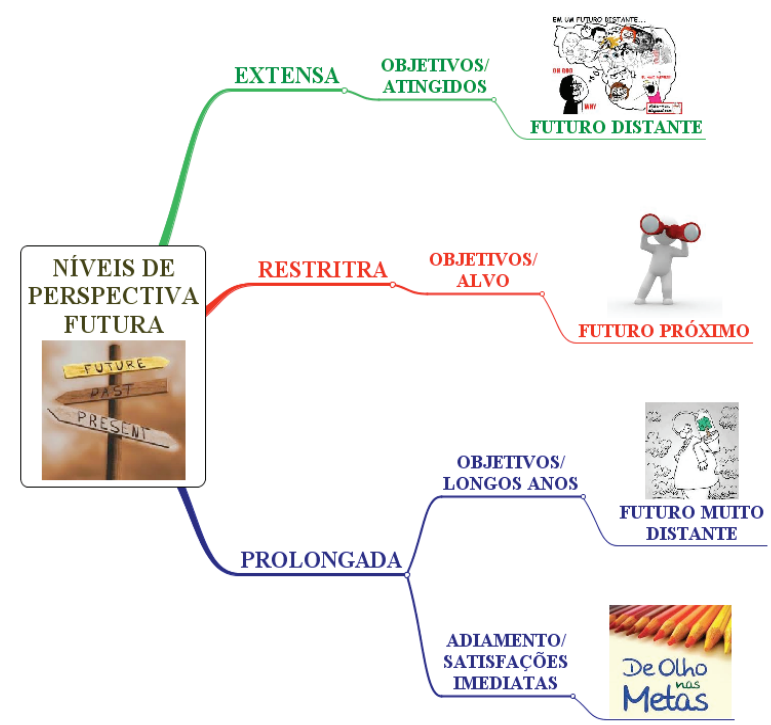

Fonte: Elaborada pela autora a partir de Lens (1993 apud SANTOS, 2011, p. 400).

O conhecimento desses níveis corrobora para uma formação inicial docente pautada na aplicação do conhecimento reflexivo que abrange o cerne do processo educativo, residindo na escolha dos padrões de desenvolvimento humano, visando atender às características da sociedade e dos contextos inseridos nela. Nesse cenário de gerenciar dilemas, "[...] a consciência profissional consolida-se e desenvolve-se, explicitando-os, clarificando-os, estabelecendo as suas ligações, extraindo as derivações das opções que se agrupam em torno destes dilemas" (SACRISTÁN, 1999, p. 87).

Evidentemente, a atividade docente tem relação com conhecimentos científicos e emocionais, o que não representa a exclusividade do conhecimento científico. 0 autor indica que é peculiar observar a relação que há entre explicações e prática e indaga: qual a forma de conhecimento que se evidencia na prática? 0 próprio autor responde:

0 ensino como atividade em que se aplica o conhecimento científico é uma proposta com grande tradição acadêmica, especialmente neste século, reforçada pela visão técnico-positivista de entender a relação teoria-prática. [...] a pedagogia desenvolveu-se como uma aplicação da psicologia. Segundo este modelo, a pedagogia agrupa um conjunto de aptidões práticas que permitir aplicar os conhecimentos produzidos por uma série de ciências básicas. A formação de professores está impregnada desta lógica, que concebe a realidade como um campo de aplicação; a prática tem pouca importância enquanto fenômeno preexistente, a não ser na perspectiva de uma regulação (correção) baseada no conhecimento científico. (SACRISTÁN, 1999, p. 84).

A partir dessa assertiva, pode-se inferir que a formação de professores tem sido orientada por uma abordagem dedutivista que considera a diversidade de saberes, mesmo que separados e longe da prática, um caminho para capacitar os professores à profissão docente na perspectiva de executar as atividades dentro dos parâmetros das ciências de base. Esse cenário não reconhece a necessidade das contribuições pessoais e dos processos motivacionais.

Entretanto, Schön (2008) garante que a formação profissional docente vincula teoria e prática para um ensino reflexivo que se sustenta no processo de reflexão-na-ação. Esse argumento perpassa pela ideia de os professores atuarem como desenhadores reflexivos de situações práticas. Em outras palavras, ele critica o academicismo, o excesso de teorias, a valorização exagerada da ciência básica, a pouca aplicabilidade do conhecimento e das produções acadêmicas na busca de soluções para os problemas. Essa teoria nos remete a argumentar acerca da relevância dos processos motivacionais nas licenciaturas, haja vista a concepção de que apenas o conhecimento científico não desenvolve a capacidade do ser humano refletir sobre as inter-relações sociais e educacionais.

Em síntese, o espaço de formação inicial deve possibilitar ao professor a identificação dos processos pedagógicos e emocionais que ocorrem no nível das relações sociais mais amplas e não apenas nos espaços escolares, mas na conjuntura social, também. Além 
disso, torna-o capaz de conduzir uma prática pedagógica reflexiva que supera a atual organização curricular em disciplinas estanques, por meio da construção coletiva de formas pedagógicas que tomem a motivação como parte das atividades educativas.

\section{ALGUMAS PALAVRAS FINAIS}

A formação inicial de professor na perspectiva reflexiva permite fazer uma análise de que a partir da prática emerge uma nova caminhada em que o conhecimento formal não se limita a deduzir as práticas. Pelo contrário, o professor passa a equacionar suas práticas, escolher temáticas de reflexão, propor alternativas de intervenção, criando estilos de debates, a lidar com pessoas, acompanhar seus processos de formação de produção e apreensão de saberes e valores, principalmente nos contextos educativos dos processos emocionais.

Dessa forma, infere-se que a formação como uma atividade reflexiva, um fazer fruto de um processo de deliberação, um refletir da prática estimulada pela interação motivacional professor-aluno em diferentes situações, ainda, é um desafio na formação inicial do professor na sociedade na qual se vive.

A discussão, aqui, proposta conduz a pensar/refletir com mais veemência a relevância de o professor ter a autonomia profissional para (re)criar a profissão docente pela formação e consolidação do espírito científico com a interação das teorias motivacionais. Isso permite declarar que há uma relação intrínseca entre a ciência pedagógica, a prática reflexiva do docente e a motivação como instrumento para uma formação diferente da que se tem atualmente. Realidade essa que justifica a presença do estudo das teorias motivacionais na formação básica dos professores.

\section{REFERÊNCIAS}

ARROYO, Miguel G. Oficio de mestre: imagens e auto-imagens. Petrópolis: Vozes, 2000.
AZZI, Sandra. Trabalho docente: autonomia didática e construção do saber pedagógico. In: PIMENTA, Selma Garrido (Org.). Saberes pedagógicos e atividade docente. São Paulo: Cortez, 2000.

BRASIL. Lei de Diretrizes e Bases da Educação Nacional, nº 9.394, de 1996. Brasília, 1997.

ELLIOTT, Emily; DWECK, Carol S. Goals: An approach to motivation and achievement. Journal of Personality and Social Psychology, Washington DC, v.54, n.1, Jan. 2005, p. 5-12.

FOSSATTI, Paulo. A motivação como elemento substancial para a produção de sentido na docência. In. SANTOS, B. S. dos; CARREÑO, Á. B. A motivação em diferentes cenários. Porto Alegre: EDIPUCRS, 2010.

HUERTAS, Juan António. Motivación: querer aprender. Buenos Aires: AIQUE: 2001.

KUENZER, Acacia Zeneida. A formação de educadores no contexto das mudanças no mundo do trabalho: novos desafios para as faculdades de educação. Educ. Soc. v.19, n.63, Campinas Aug. 1998. Disponível em: <http://dx.doi.org/10.1590/S0101-733019980 002 00007>. Acesso em: 16 jun. 2011.

LENS, Willy. Future time perspective and motivation: Theory and research method. Louvain: Presses Universitaires de Louvain, 1993.

NUTTIN, Joseph. Théorie de la motivation humaine.

Paris: Presses Universitaires de France, 1985.

PEREIRA, Marcos Villela. Sociedade, trabalho e motivação na vida contemporânea. In. SANTOS, B. S. dos; CARREÑO, Á. B. A motivação em diferentes cenários. Porto Alegre: EDIPUCRS, 2010.

PIMENTA, Selma Garrido. Saberes pedagógicos e atividade docente. 4.ed. São Paulo: Cortez, 2005. 
SACRISTÁN, J. G. Consciência e acção sobre a prática como libertação profissional dos professores. In: NÓVOA, António. Profissão professor. Portugal: Porto, 1999.

SANTOS, B. S. dos. Indicadores de qualidade e motivação discente. In: Morosini, Marilia Costa. Qualidade na educação superior: reflexões e práticas investigativas. Porto Alegre: EDIPUCRS, 2011.

SANTOS, B. S. doS; ANTUNES, D. D. Vida adulta, processos motivacionais e diversidade. Educação, Porto Alegre: PUCRS, ano XXX, v.61, n.1, jan./ abr. 2007a, p. 149-164.
SANTOS, B. S. dos; STOBÄUS, C. D.; MOSQUERA, J. J. M.; Processos motivacionais em contextos educativos. Revista Educação, n. especial, ano XXX. Porto Alegre, 2007b.

\section{$\mathrm{SCHÖN}$, Donald A. Educando o profissional re-}

flexivo: um novo design para o ensino e a aprendizagem. Porto Alegre: Artmed, 2008.

TIMM. Edgar Zanini. Refletindo sobre a motivação docente: sou professor, porque isso me faz bem. In. SANTOS, B. S dos; CARREÑO, Á. B. A motivação em diferentes cenários. Porto Alegre: EDIPUCRS, 2010. 